\title{
EDEECONOMIAE 竧AGRONEGÓCIO
}

ISSN impresso: 1679-1614

ISSN online: $2526-5539$

Vol. 18 | N. 2 | 2020

EDITORIAL

\section{IMPACTOS DA CRISE DO CORONAVÍRUS NAS CADEIAS PRODUTIVAS DE FRUTAS E HORTALIÇAS BRASILEIRAS}

\author{
João Ricardo Ferreira de Lima*1 \\ ORCID: 0000-0001-6045-9794 \\ E-mail: joao.ricardo@embrapa.br
}

\author{
Maria Thereza Macedo Pedroso*2 \\ ORCID: 0000-0002-7589-186X \\ E-mail: $\underline{\text { maria.pedroso@embrapa.br }}$
}

(*) Empresa Brasileira de Pesquisa Agropecuária - Embrapa, Brasília, DF - Brasil (1) Embrapa Semiárido, Petrolina, PE; (2) Embrapa Hortaliças, Brasília, DF

\section{Introdução}

O vírus SARS-CoV-2 (Severe Acute Respiratory Syndrome Coronavirus 2) ou, em português, Coronavírus da Síndrome Respiratória Aguda Grave 2, causa uma doença infecciosa cujos sintomas mais comuns são febre, tosse e dificuldade em respirar. O que se sabe até o momento é que o SARS-CoV-2 (ou mais conhecido como "novo coronavírus") foi identificado pela

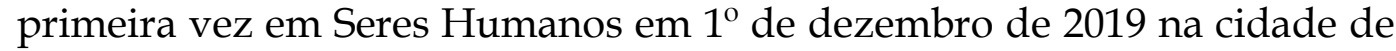
Wuhan, província de Hubei, na China.

O primeiro país ocidental fortemente atingido pelo coronavírus foi a Itália. Em seguida, o vírus se alastrou para o resto do mundo e, em 11 de março de 2020, a Organização Mundial de Saúde (OMS) declarou que o mundo estava diante de uma pandemia (enfermidade epidêmica amplamente disseminada). A alternativa recomendada pela OMS para retardar a velocidade com que o novo vírus se alastra é o isolamento social conjugado com o uso de máscaras e a intensificação de higienização de pessoas e locais, pois, até o momento, não há vacina (algumas estão em fase avançada de desenvolvimento) e tampouco medicamentos que tenham efeito comprovado cientificamente.

Foi no dia 26 de fevereiro que se confirmou o primeiro caso do novo Coronavírus no Brasil e, duas semanas depois, 52 casos já estavam confirmados. Tudo indica que os primeiros casos de contágio de brasileiros ocorreram em suas viagens para a Europa no início de 2020. O Brasil, 
portanto, teve a vantagem inicial de conseguir observar as consequências de um crescimento muito rápido do número de casos em outros países e tomar providências. Os Governos Federal, Estaduais e Municipais imediatamente reagiram e seguiram as recomendações da OMS. As aulas foram suspensas e locais onde aglomeram pessoas, como shoppings, academias, salões de cabelereiros, cinemas, restaurantes e lojas, fechados. As medidas para evitar contato social se intensificaram até que foram fechados todos os serviços considerados como não essenciais.

Não se sabe até quando a atual crise sanitária perdurará. Por consequência, ainda não se pode ter a real dimensão do impacto negativo da pandemia sobre a economia nacional, o que causa uma sensação de apreensão e insegurança difusa entre os brasileiros. Há algumas previsões, todas pessimistas. Por exemplo, o Boletim Focus divulgado pelo Banco Central do Brasil tem trazido estimativas de forte retração no Produto Interno Bruto (PIB) brasileiro.

No entanto, é possível organizar algumas informações sobre o que vem ocorrendo em vários subsetores da economia brasileira. A Revista de Economia e Agronegócios optou por refletir sobre os principais problemas decorrentes da atual crise relacionados com um importante subsetor da economia agrícola brasileira, o de frutas e hortaliças, objeto de pesquisa dos autores do presente documento. Dessa forma, o que é aqui apresentado é resultado da interpretação conjunta dos autores sobre as informações coletadas em bases de dados das Centrais de Abastecimento e em entrevistas realizadas junto aos diversos agentes das cadeias produtivas de frutas e hortaliças sobre a crise em questão.

\section{Principais aspectos das cadeias produtivas de frutas e hortaliças}

Relevantes especificidades das cadeias produtivas de frutas e hortaliças devem ser destacadas. A primeira característica é que as frutas e hortaliças são produtos altamente perecíveis, o que impede que sejam armazenados por um período prolongado, como ocorre com os grãos. Mesmo que haja exceção, como a maçã, que fica armazenada por alguns meses em câmara fria, às frutas não deixam de ser consideradas altamente perecíveis. A segunda característica é que, de uma forma geral, a produção, a colheita, o acondicionamento, o transporte e a comercialização dependem de muita mão de obra. A terceira característica é que, em função da sua alta perecibilidade, importante proporção das frutas e hortaliças dependem da "cadeia do frio", mas que não está totalmente desenvolvida no Brasil, como ocorre em países ditos "mais avançados".

A quarta característica é que frutas e hortaliças não se assentam sobre a produção de uma única mercadoria, como as cadeias produtivas da soja ou do frango. São compostas por inúmeros produtos. Portanto, são, na verdade, várias cadeias produtivas. Algumas estão mais estruturadas, como as de manga, uva, melão, cenoura e tomate rasteiro voltado para a indústria de processamento de alimentos. Outras estão menos estruturadas como as de banana e mandioquinha-salsa. 
Muitas das cadeias produtivas de frutas e hortaliças no Brasil vêm se transformando em complexas estruturas econômicas, financeiras e organizacionais. São compostas por um conjunto de agentes econômicos, tais como as indústrias de insumos, maquinários, embalagens e processamento de alimentos, os agricultores e as empresas de logística, transporte, atacado e varejo, entre outros. Todos esses agentes econômicos podem se diferenciar muito, de acordo com as escalas de operações, o nível tecnológico e o porte econômico: desde um estabelecimento agropecuário que conta com a mão de obra apenas dos membros da família, obtendo renda relativamente baixa, até aquele com muitos empregados; daquele com menor intensidade tecnológica até aquele com maior intensidade; de um estabelecimento agropecuário cuja produção é voltada para o comércio local até aquele que produz para a exportação; do que obtém baixíssima receita até o que obtém grande receita; desde uma pequena agroindústria familiar a uma filial de indústria multinacional de processamento de alimentos; de uma banca de feira até uma rede internacional de supermercados; de um pequenino à uma rede de restaurantes.

Por fim, a quinta característica tem relação com os canais de comercialização, que são inúmeros. Ainda que os agentes econômicos das cadeias produtivas de frutas e hortaliças se diferenciem muito de forma gradativa, conforme apresentado acima, os autores optaram por apresentar cada canal de produção de forma binária (grande/pequeno, especializada/diversificada) para possibilitar a apresentação de um panorama geral de forma didática em curto espaço. A seguir, são apresentadas tais peculiaridades, mas é importante destacar que são concepções extremamente gerais.

As grandes indústrias de processamento de alimentos e as grandes empresas de produtos minimamente processados necessitam ter fluxo contínuo de entradas de matéria prima. Precisam que os produtos mantenham uma série de atributos para serem processadas. Como exemplos, têm-se o tomate e a pimenta para a indústria de molhos ou a laranja para a indústria de sucos. É comum, portanto, que haja contrato formal entre a indústria ou empresa e os agricultores para que os produtores forneçam em quantidade e qualidade os produtos para a indústria. Da mesma forma, as pequenas indústrias de processamento de alimentos e as pequenas empresas de produtos minimamente processados precisam ter fluxo contínuo de entradas de matéria prima. Nesse caso, muitas vezes, a matéria prima é produzida no mesmo estabelecimento agropecuário onde se enquadra a pequena indústria ou a pequena empresa. Também pode comprar a matéria prima dos estabelecimentos agropecuários vizinhos. Aqui o mais comum é a que não haja contrato formal, mas contratos informais, ou como se diz popularmente, "contrato de boca". Tanto as indústrias de processamento como as empresas de produtos minimamente processados, indiferentemente do porte econômico e físico, comercializam seus produtos para restaurantes e para empresas de varejo de todos os portes econômicos. 
As grandes redes de supermercados normalmente possuem Centrais de Distribuição (CDs) exigem hortaliças de melhor qualidade em termos visuais (de tamanho e formatos padronizados, sem qualquer dano externo ou interno). Em alguns casos, estabelecem também contrato com os produtores ou com as empresas lavadoras. É relevante destacar que algumas hortaliças são lavadas fora dos estabelecimentos agropecuários onde são cultivadas e apresentam todo tipo de porte físico e econômico. Como exemplos de hortaliças que são lavadas, têm-se a cenoura, a batata e a mandioquinha-salsa.

As empresas de atacado, popularmente chamadas de "box", normalmente se localizam nas Centrais de Abastecimento (Ceasas) ou próximo a elas. Para melhor compreensão, os autores as distinguem em dois grandes grupos: a) empresas de atacado especializadas na comercialização de uma determinada hortaliça ou fruta; b) empresas de atacado diversificadas são aquelas que comercializam diversas hortaliças ou frutas. As "especializadas" são de maior porte econômico. Seus clientes são em grande parte os supermercados de médio e pequeno porte que não possuem CDs. Por tudo isso também são exigentes. Quase sempre compram os produtos diretamente dos agricultores por meio de contratos, na maioria das vezes, informais. Por outro lado, as "diversificadas" são de menor porte econômico e, de forma geral e seus compradores são feirantes, varejões, quitandas e restaurantes.

Há também o comércio internacional que se concentra principalmente na uva e na manga produzidas no Vale do Rio São Francisco, no melão produzido no Rio Grande do Norte e no mamão produzido no Espírito Santo. Seus compradores são, na maioria das vezes, países europeus e apresentam maiores exigências, inclusive em termos de selos ambientais e sociais. Há a comercialização direta por meio de feiras de produtores, nas quais os produtores comercializam seus produtos. Compras por associações de consumidores que financiam a produção em estabelecimentos de pequeno porte econômico e compram os alimentos. Mais recentemente foram criadas plataformas de comercialização virtual. Por fim, existem as compras institucionais em especial, o PAA (Programa de Aquisição de Alimentos) e o PNAE (Programa Nacional de Alimentação Escolar).

De uma forma muito geral, é possível afirmar que o produtor que consegue oferecer produtos de melhor qualidade em termos visuais é majoritariamente aquele de grande porte econômico, com maior nível tecnológico e com alta capacidade de gestão. Normalmente emprega mais mão de obra e seus estabelecimentos agropecuários são maiores em termos de área. Por outro lado, as frutas e hortaliças de qualidade inferior acabam sendo comercializadas para os canais de comercialização menos exigentes. Geralmente, apresentam menor nível tecnológico, baixa capacidade de gestão e são majoritariamente de pequeno porte econômico. Em termos muito gerais, é normalmente classificado como "agricultor familiar" por empregar poucos ou nenhum trabalhador e porque seus estabelecimentos agropecuários apresentam áreas menores (e esses são critérios para classificá-los como "familiares" de acordo com a legislação nacional). 


\section{Principais impactos da crise do Coronavírus}

As cadeias produtivas de frutas e hortaliças no Brasil têm vários desafios com (1) a adequação às regras de rastreabilidade; (2) o comércio ilegal de defensivos agrícolas; (3) o registro de defensivos agrícolas para as culturas denominadas minor crops e para as frutas exportadas; (4) as perdas de produtos ao longo das cadeias produtivas; (5) o baixo consumo de frutas e hortaliças pelos brasileiros; (6) a padronização dos produtos; (7) a qualidade dos produtos em geral e também dos minimamente processados; (8) o custo de produção; (9) a logística e (10) o desenvolvimento por completo da "cadeia do frio".

Todos esses desafios são amplamente reconhecidos pelo setor privado e são objetos de discussão e de demandas de políticas públicas nas Câmaras Setoriais de Hortaliças e de Fruticultura mantidas pelo Ministério da Agricultura, Pecuária e Abastecimento (Mapa). Além dessa série de desafios, é sabido que a atividade agropecuária envolve diversos riscos. Todos os anos espera-se que ocorra algo que não se pode controlar. Normalmente, os acontecimentos são relacionados com o clima que afeta a safra, os concorrentes no mercado internacional, a macroeconomia ou o próprio funcionamento do mercado de frutas e hortaliças. O ano de 2020 começou com muitas expectativas positivas para muitos setores agrícolas nacionais. Contudo, um novo e grande desafio surgiu repentinamente e se tornou preeminente: enfrentar os possíveis problemas sanitários e econômicos desencadeados pelo avanço do Covid-19 no Brasil e no Mundo.

Cerca de quinze dias após a declaração da OMS foi assinada a Portaria $\mathrm{n}^{\mathrm{o}}$ 116 do Mapa, de 26 de março de 2020, que dispõe sobre "os serviços, as atividades $\mathrm{e}$ os produtos considerados essenciais para o pleno funcionamento das cadeias produtivas de alimentos e bebidas, visando assegurar o abastecimento e a segurança alimentar da população enquanto perdurar o estado de calamidade pública decorrente da Covid-19". A Portaria ressalva que todas as atividades devem considerar rigorosamente as diretrizes de segurança mínima estabelecidas para conter o avanço do vírus, apresentadas pelo Ministério da Saúde, bem como as prescrições previstas no Regulamento Sanitário Internacional. Ainda que a sociedade brasileira conte com a Portaria $n^{\circ} 116$ do Mapa, impactos da pandemia ocorreram no setor de frutas e hortaliças.

Como impactos mais imediatos da pandemia têm-se alguns exemplos relacionados com os transportes de trabalhadores, insumos e produtos. Nas primeiras semanas de isolamento, em alguns Municípios, ocorreram impedimentos das entradas regulares de ônibus provenientes de outros locais. Dessa forma, alguns deles foram impedidos de transportar os trabalhadores até seus locais de trabalho. Muitos atuam na produção ou no beneficiamento de frutas e hortaliças e residem em municípios ou até em Unidades da Federação diferentes daqueles onde se localizam os estabelecimentos agropecuários nos quais exercem suas atividades laborais. É o que ocorre, por exemplo, em grandes fazendas produtoras de alho em Minas Gerais, as quais dependem de trabalhadores que regularmente têm sido contratados em algumas Unidades da Federação nordestinas. 
Menos problemática foi a entrada de fornecedores de insumos agrícolas e embalagens nos diversos Municípios. Porém, a mera hipótese de que esses produtos não pudessem chegar nos estabelecimentos agropecuários causou, entre os agricultores, receio de ocorrer retardo no investimento em novos plantios. Foram recorrentes os questionamentos, tais como "Devo continuar investindo em mão de obra e tempo na produção? Como vou comercializar? Como vou pagar o crédito?". O fato é que se concretizasse o atraso no plantio, o problema não seria apenas dos agricultores, pois o cronograma de produção não seria seguido conforme o esperado nos milhares de estabelecimentos agropecuários e causaria atraso na colheita e, por consequência, problemas de abastecimento.

Por tudo isso, é possível afirmar que "as entradas nos municípios" foram consideradas pontos nevrálgicos nas primeiras semanas de isolamento social para o abastecimento de frutas e hortaliças. Afinal, são mais de 5 mil municípios no Brasil. Se cada município optasse por uma regra diferente sobre trânsito de pessoas e de produtos, o abastecimento da população se concretizaria num desafio. Tudo indica que essa questão foi superada ainda no mês de março, inclusive a Confederação Nacional de Municípios (CNM) disponibilizou Nota Técnica, no dia 30/03/20, na qual apresentava “orientações para a garantia do abastecimento nos Municípios em decorrência da Covid-19".

Também nas primeiras semanas do isolamento, muitos caminhoneiros que transportam todo o tipo de carga, inclusive frutas e hortaliças, insumos agrícolas e embalagens, tiveram dificuldade para se alimentar, já que a maioria dos restaurantes foram fechados. Contudo, como trata-se de uma categoria profissional bastante organizada, conseguiram chamar a atenção dos meios de comunicação e esse problema foi solucionado por meio de diversas ações de solidariedade de pessoas, das organizações sem fins lucrativos, das empresas que possuem concessão das estradas, dos militares e do Departamento de Estradas e Rodagens (DER). Até que os próprios restaurantes passaram a oferecer a opção de entregar as refeições para serem consumidas fora dos estabelecimentos.

De acordo com o tipo de produto, verificou-se um descompasso. Nos primeiros meses do ano, por exemplo, a comercialização de plantas ornamentais como um todo sofreu forte queda. No entanto, com o passar do tempo, houve uma clara diferenciação; As flores de corte continuaram com baixa comercialização. Estão relacionadas diretamente com o convívio social. São muito utilizadas em decorações de festas e em velórios. As festas foram adiadas e os velórios foram reduzidos. As plantas de vaso experimentaram um aumento nos últimos meses. Muito provavelmente, as pessoas estando mais em casa sentem o desejo de deixá-las mais agradáveis e estão adquirindo mais destas flores.

A redução na comercialização de "hortaliça folhosa" (alface, rúcula, couve, por exemplo.) foi muito maior do que a de "hortaliça não folhosa" (cenoura, batata, cebola etc.). Constatou-se que essa última teve uma queda mais lenta e menor que a primeira. Muito provavelmente a situação das "hortaliças folhosas" seja mais delicada porque o setor de alimentação (restaurantes e 
refeitórios) foi forçado a fechar o atendimento presencial. Ainda que os "deliveries" e os "marmitex" estejam funcionando, não utilizam (ou usam pouco) muitas "folhosas" (saladas), pois elas murcham muito rapidamente. Da mesma forma, o consumidor está indo menos vezes ao supermercado e comprando menos "folhosas", pois são mais perecíveis do que as "não folhosas".

Verificou-se também um aumento do consumo de algumas frutas ricas em vitamina $C$, indicando a hipótese de que o consumidor considera que sua ingestão possa fortalecer o seu organismo, caso seja contaminado com o novo Coronavírus. Identificou-se preferência por frutas menos perecíveis. Muito provavelmente, pela mesma justificativa relacionada com as "hortaliças não folhosas", ou seja, para evitar ir mais vezes ao supermercado.

Os supermercados foram considerados "serviços essenciais" no período da crise, ou seja, não fecharam. Os restaurantes ficaram fechados todos os últimos meses para atendimento presencial. Inclusive, há relatos de que alguns restaurantes não conseguiram pagar as empresas de atacado e essas não puderam pagar os agricultores. As escolas ainda estão fechadas em sua maioria (públicas e privadas). Dessa forma, até a compra dos produtos da agricultura para o Pnae foi prejudicada. Portanto, verificou-se que os produtores que mantém contratos formais ou até informais estabelecidos com indústria de processamento de alimentos, empresas de alimentos minimamente processados, supermercados, empresas de atacado especializadas, associações de consumidores e empresas de plataformas digitais tenham maior resiliência, diante da atual crise. Por outro lado, os produtores que dependem dos canais de comercialização "empresas de atacado diversificadas", feiras e compras institucionais têm menor capacidade de resistir às dificuldades impostas pela atual crise. Por tudo isso, de grande gravidade é a realidade comum entre muitos responsáveis por estabelecimentos agropecuários de pequeno porte econômico que são, de forma geral, classificados como "agricultores familiares". Dessa forma, surge uma hipótese a ser confirmada no futuro: os "agricultores familiares" sairão ainda mais fragilizados dessa crise.

\section{O caso da fruticultura do Vale do Rio São Francisco}

Em relação às frutas, as informações aqui representam exclusivamente a realidade do Vale do Submédio São Francisco. Esse é o maior polo nacional produtor de frutas do país. Por contar com as águas do Rio São Francisco para a irrigação, tem a característica de produzir frutas durante os 12 meses do ano. No primeiro semestre de cada ano, ocorre a maior taxa média de precipitação o que aumenta a probabilidade de ocorrência de pragas e doenças. Como os países importadores de frutas brasileiras restringem o limite máximo permitido de resíduos de produtos químicos, muitos produtores optam por uma menor produção nos primeiros seis meses do ano para evitar que a qualidade da fruta seja afetada pela impossibilidade de usar produtos químicos. Dessa forma, no segundo semestre ocorre o pico de produção. 
Por ser uma região do interior do Nordeste, o aumento do número de casos de Covid19 ocorreu mais tarde, em meados de maio. Mesmo assim, quando os governos estaduais começaram a implantar as medidas de restrição de circulação e as medidas de prevenção foram divulgadas, as empresas adotaram imediatamente os protocolos de prevenção de contaminação por meio de instalação de novas pias para lavar as mãos, distribuição de álcool gel, obrigatoriedade do uso de máscaras e higienização diária de ônibus. Até o momento, não se tem informação de grande quantidade de trabalhadores infectados em nenhuma das empresas da região que levasse a medidas de fechamento de fazenda ou algo neste sentido. Vale ressaltar que o Sindicato dos Trabalhadores Rurais da região é extremamente forte e atuante, com quase quarenta mil trabalhadores sindicalizados. Dessa forma, é possível afirmar que a menor produção e a consequente redução na oferta de frutas dessa região, no primeiro semestre, foi reflexo das condições climáticas desfavoráveis e não algum tipo de impacto do novo coronavírus.

Em termos de comercialização, contudo, diversas situações ocorreram, desde aqueles produtores que tiveram forte prejuízo até outros que alcançaram excelentes lucros. Tudo dependeu do momento em que a colheita foi realizada. Entre as semanas 12 e 15 de 2020 (segunda quinzena de março e primeira quinzena de abril), a situação dos produtores foi bastante difícil. Foi o momento em que todos ainda tentavam entender o que estava ocorrendo, "o que era esse novo vírus" e "como se adaptar ao isolamento", ou seja, uma enorme incerteza em relação ao futuro. Nesse momento, contratos foram cancelados e muitos produtores acabaram não encontrando compradores para as suas frutas. Os preços foram abaixo da média dos últimos anos.

As empresas de atacado, por seu lado, não conseguiram mais seguir o planejamento prévio baseado no comportamento dos anos anteriores. As semanas alternavam entre grande e baixa demanda. Assim, ou sobrava fruta no atacado ou faltava. As empresas de varejo também foram afetadas pois houve, na verdade, uma mudança no comportamento do consumidor. Assim que se teve início o primeiro período da quarentena, ocorreu uma corrida aos supermercados e a compra de uma grande quantidade de alimentos, hortaliças e frutas em geral. Muitos consumidores se prepararam para ficar até 30 dias sem retornar ao supermercado. As plataformas digitais de compras online em supermercados, varejões de frutas e hortaliças ou não existiam ou não tinham a capacidade necessária para atender uma grande demanda. Este comportamento, com o passar das semanas, vem mudando gradualmente, e os consumidores aumentaram a ida aos supermercados, mas não na mesma frequência de antes da pandemia.

Além de sair mais de casa para ir às compras, depois das primeiras semanas da quarentena, o consumidor passou a buscar se alimentar melhor. Muitas famílias começaram a preparar seus próprios alimentos, pois estavam em casa trabalhando na modalidade home office, os restaurantes estão fechados e há receio de ser contaminado através das embalagens dos produtos de delivery etc. No final de abril, pode-se dizer, que já existia uma melhor compreensão do "novo normal" em relação ao mercado de frutas. Os preços 
passam a refletir isto. Um aumento da demanda tanto doméstica quanto externa fez os preços ao produtor crescerem e, durante várias semanas, ultrapassarem a média histórica.

A redução do consumo de frutas que ocorreu em hotéis, pousadas, restaurantes, bares, escolas, mais do que foi compensada pelo crescimento das vendas das redes de supermercado e frutarias. Os volumes de manga e uva exportados no primeiro semestre foram menores do que em 2019, mas estão acima da média dos últimos 8 anos. Os preços das frutas exportadas não são mais elevados em razão da qualidade da fruta, que é inferior pelos problemas sanitários causados pelo excesso de chuvas no Vale do São Francisco.

Do ponto de vista da exportação, a maior dificuldade foi um curto período em que a quase totalidade dos contêineres mundiais ficaram retidos na China. Passada esta dificuldade, nem mesmo os preços mundiais de frete marítimo tiveram significativa mudança. Por outro lado, os envios de frutas áreas sofreram forte impacto. No Vale do São Francisco, contudo, apenas cerca de $7 \%$ do que é exportado vai pelo modal aéreo. Grande parte das frutas aéreas embarcam nos espaços disponíveis dos aviões de passageiros. Como o setor de transporte aéreo foi duramente afetado pela crise do coronavírus, pois houve muita desistência de viagens, muitos voos foram cancelados, acarretou uma grande dificuldade em fazer os envios de frutas por aviões, que é uma fruta com maior valor agregado, que chega praticamente pronta para o consumo. Até o momento, estas dificuldades ainda permanecem o que eleva o custo de envio e praticamente inviabiliza o negócio.

\section{Considerações finais}

Esse editorial apresentou os principais aspectos das cadeias produtivas de frutas e hortaliças no Brasil e alguns problemas decorrentes da crise do novo coronavírus sobre esse setor, até o momento (início de agosto de 2020). Alguns já foram superados, outros ainda não. A atual crise certamente irá deixar marcas históricas de forma a se poder observar dois grandes períodos, o "AC (antes do Coronavírus) e o DC (depois do Coronavírus)". Uma hipótese é que os agricultores denominados "familiares" saiam ainda mais fragilizados dessa crise.

Pode-se considerar que em comparação com outros setores da economia, o de hortaliças e frutas acabou tendo menores impactos no geral. A principal questão foi o tempo que se levou para entender melhor o comportamento da demanda durante o período da quarentena, suas flutuações e as novas preferencias dos consumidores. Absorvida esta compreensão, a adaptação pode ser considerada como rápida.

Contudo agora se está mais próximo de enfrentar um novo período de dificuldades e de novas necessidades de adaptações. Nesta nova fase os efeitos serão advindos da questão da queda de renda das famílias e do aumento do desemprego. Ocorrendo o fim do repasse de renda via auxílio emergencial para as famílias, que ajudou muitas a sair da pobreza, a cesta 
de produtos consumidos tem que mudar. Quando a renda familiar reduz, as frutas em geral acabam sofrendo queda de consumo, se mantendo apenas aquelas com menores preços, como a banana. $\mathrm{O}$ mesmo ocorre com algumas hortaliças. Assim, espera-se um segundo semestre com maiores dificuldades para os produtores até o momento em que chegar uma vacina, as pessoas estiverem imunizadas e a economia puder voltar a reagir, com a volta das contratações e aumento da renda. 